\title{
La evolución de la tarjeta postal y las guerras contemporáneas: dos caminos encontrados (1869-1945)
}

\section{The evolution of the postcard and Modern Wars: Two paths encountered (1869-1945)}

\author{
José Manuel López \\ Universidad de Castilla La Mancha, España \\ JoseManuel.Lopez@uclm.es
}

\begin{abstract}
Resumen:
La tarjeta postal ha formado parte de nuestra vida cotidiana hasta hace relativamente poco tiempo. Esa fuerte presencia, sumada a su carácter visual y textual, la han posicionado en un lugar destacado como testigo de un sinfín de aspectos acontecidos en el último siglo y medio de nuestra historia. Dentro de sus múltiples ámbitos de actuación, la relación que ha demostrado tener con el mundo de la guerra resulta mucho más estrecha de la que tradicionamente se le ha atribuido. Su misma puesta en circulación o sus altos niveles de producción durante la Gran Guerra, coincidiendo con su edad de oro, muestran un fuerte vínculo con el mundo bélico al que no se le ha proporcionado la atención que precisa. Con el fin de determinar hasta qué punto la guerra pudo influir en la evolución de estas pequeñas cartulinas, se presenta un estudio centrado en la producción y distribución de estos soportes en distintos enfrentamientos armados desarrollados entre la segunda mitad del siglo XIX y mediados del XX, desde la guerra francoprusiana hasta la Segunda Guerra Mundial.
\end{abstract}

\begin{abstract}
:
The postcard has been part of our daily life until recently. This strong presence, added to its visual and textual character, has placed it in a remarkable position as a witness of a great number of aspects that have taken place in the last 150 years of our history. Within its many fields of influence, the connection it has demonstrated with the world of war is much closer than has traditionally been attributed to it. Its release during the francoprussian war or the high levels of production during the Great War, coinciding with its golden age, show a strong link which has not received the attention it needs. In order to determine to what extent war may have influenced the evolution of these small cards, a study is presented which focuses on the production and distribution of these media in different armed confrontations between the second half of the 19th century and the first half of the 2oth century, from the Franco-Prussian War to the Second World War.
\end{abstract}

Palabras clave:

Tarjeta postal; guerras contemporáneas; Propaganda; patrimonio documental

Keywords:

Postcard; modern wars; Propaganda; documental heritage 


\section{Introducción}

La tarjeta postal constituye uno de los más notables avances en el mundo de la correspondencia y las ventajas que demostró, desde el mismo momento en el que se puso en circulación a mediados del siglo XIX, la posicionaron en un lugar privilegiado dentro de los sistemas de correos de todo el globo. Si bien en sus inicios se presentó como una medida que abarataba los costes de los envíos postales, con el tiempo se fue convirtiendo en un verdadero objeto cultural sobre el que han quedado recogidos multitud de elementos dignos de ser analizados. En gran medida, esto ha sido posible gracias a los miles de millones de personas que acudieron a estas pequeñas cartulinas como medio para seguir en contacto con sus seres queridos sin ser conscientes de que con el paso del tiempo se convertirían en testigos del pasado.

La genialidad que presenta frente a otros soportes radica, esencialmente, en su capacidad para atesorar, en unos pocos centímetros cuadrados de papel, información tanto escrita como visual. Esta particularidad la ha posicionado como un verdadero tesoro documental que permite el estudio de las realidades sociales de los últimos ciento cincuenta años de nuestra historia por medios de esas dos perspectivas diferenciadas a la par que complementarias. Así, al incalculable valor que aportan los mensajes plasmados en ellas, le sumamos su capacidad para consolidarse como un verdadero catálogo visual de los últimos 150 años similar al que han conformado la fotografía y otros medios de parecidas características (Guereña, 2005, p. 35 y Riego, 2019, p. 21).

Con esta idea de fondo, en las próximas páginas se plantea un estudio en el que se recoge la evolución que experimentó el citado soporte desde 1869, año de su puesta en marcha, hasta 1945, momento en el que comenzó su verdadero declive tras el fin de la Segunda Guerra Mundial y en el que se le aplicaron las últimas reconfiguraciones que la llevaron a adoptar el aspecto actual.

Dentro de la dilatada trayectoria con la que cuenta la postal, se ha detectado una estrecha vinculación con los contextos bélicos, de ahí que el objetivo principal que se estableció al comienzo de la presente investigación fuera el de conocer hasta qué punto los conflictos armados pudieron influir en su 
evolución. Precisamente, el rasgo singular que proporciona este estudio es la relación que se establece entre la postal y las guerras contemporáneas. De esta manera es posible distanciarse de las tradicionales aportaciones en torno a la tarjeta postal que, siempre de una forma precisa y detallada, han presentado los principales hitos que fueron moldeando el citado formato, pero han dejado al margen la importancia que tuvieron los conflictos armados en esos cambios. A esto se le suma el interés que proporciona la traducción al castellano de fragmentos de documentos oficiales relativos a la implantación o evolución de la postal en distintos territorios europeos. En definitiva, se pretendía dotar de elementos diferenciadores a un discurso sólidamente construido desde hace décadas pero que debe irse enriqueciendo a base de nuevas aportaciones que otorguen perspectivas novedosas.

La división seleccionada para estructurarlo responde, en buena medida, a la compartimentación clásica que se puede encontrar en la mayor parte de las obras de referencia sobre el estudio de la postal, quedando los distintos conflictos analizados dentro de la franja temporal correspondiente ${ }^{1}$. Así, el primer apartado cubre las décadas iniciales en las que se fueron definiendo los rasgos principales del formato y su popularidad la fue posicionando como uno de los medios preferidos por el gran público. Precisamente, ese despegue es el que nos lleva a identificar una segunda etapa caracterizada por las abrumadoras cifras de edición y de envío que alcanzaron las postales a partir de 1898 y que es recogida en un segundo epígrafe. Al tiempo que comenzaba el nuevo siglo se iniciaba también su momento de mayor esplendor, su edad de oro. Un sinfín de ejemplares llenaron los buzones de todo el mundo y, con el estallido de la Primera Guerra Mundial, se registraron las mayores cifras de circulación a causa de la fiebre postal desatada por la necesidad de mantener en contacto a los millones de soldados desplazados con sus seres queridos. Por

\footnotetext{
${ }^{1}$ Es el caso de buena parte de las obras que han conformado el corpus teórico sobre el que se ha construido la presente investigación. Dicha separación cronológica está presente, por ejemplo, en las reflexiones de trabajos plenamente consolidados desde hace tiempo como referentes internacionales: Philippen, 1977; Rapisarda, 1983 o Ripert \& Frère, 2001. Del mismo modo, dentro del ámbito español resulta pertinente señalar las conclusiones a este respecto de Almarcha, Fernández, Sánchez \& Villena, 2007; Almarcha \& Villena, 2019; Guereña, 2005; Riego, 2011 o Sánchez \& Villena, 2010.
} 
último, un tercer apartado se centra en la evolución del soporte a partir de la década de 1920, un contexto más complejo de sistematizar debido a la dispar situación que experimentaron los diferentes países hasta el estallido de la Segunda Guerra Mundial y a la ausencia de estudios que hayan superado el umbral temporal de la Gran Guerra.

Para llevar a cabo la presente investigación se ha recurrido a la consulta directa de abundantes fondos documentales depositados en tres centros de investigación de Francia y Bélgica ${ }^{2}$. Por otro lado, a pesar de que las conclusiones obtenidas se sustentan en su mayoría sobre los ejemplares analizados en tales instituciones, también se ha optado por completar el abanico de fuentes estudiadas con documentos cuya consulta se ha llevado a cabo en la Red gracias a proyectos de digitalización emprendidos por centros nacionales e internacionales.

\section{Guerra y postal en la segunda mitad del XIX (1869-1898)}

Como ya resulta conocido, fue en el marco de la Conferencia Postal celebrada en Karlsruhe en 1865 cuando Heinrich von Stephan, secretario de Estado de Correos alemán, expuso la idea de comunicarse mediante unas pequeñas hojas expedidas en forma de talonario y con el mensaje totalmente al descubierto. En ese momento, la iniciativa no fue aceptada por una serie de motivos como el temor a una reducción en los ingresos por parte del Estado, la reticencia a adoptar nuevos medios de correspondencia o la falta de intimidad que implicaba el dejar el mensaje al descubierto. Sin embargo, a pesar de contar con este primer rechazo, la idea ya había sido planteada y precisaría tan solo

\footnotetext{
2 Estas instituciones son la Bibliothèque nationale de France, la Bibliotheque royale de Belgique y el War Heritage Institute de Belgique. Entre los motivos que han llevado a seleccionar dichos centros de documentación cabe destacar la riqueza y variedad de los fondos de tarjetas postales, relacionadas con el mundo bélico, que atesoran. En el caso de la institución francesa, el hecho de que el país galo participara activamente en varios de los conflictos analizados facilitaba en gran medida la labor comparativa dentro de la evolución planteada. Por su parte, en la Bibliotheque royale de Belgique se custodia una de las colecciones más amplias de tarjetas de la Gran Guerra y en el War Heritage Institute un interesante fondo de las décadas posteriores, algo que resultaba interesante teniendo en cuenta la complicada y singular situación en la que quedó Bélgica en las dos guerras mundiales.
} 
de unos pocos años para que finalmente llegara a convertirse en una realidad. Ese momento llegó en 1869 cuando Emanuel Herrmann, un distinguido economista y profesor austriaco, publicó en el diario Neue Freie Presse un estudio bajo el título Über eine neue Art des Korrespondenzmittels der Post3, donde destacaba los beneficios que traería consigo la implantación de este nuevo soporte y la reducción de costes que supondría para los ciudadanos. Finalmente, el 1 de octubre de ese mismo año se ponía en circulación la primera tarjeta postal del mundo, una apuesta algo tímida durante los primeros días, pero que rápidamente se convertiría en un auténtico fenómeno a nivel mundial (Philippen, 1977, pp. 19-20).

Apenas un año después, en julio de 1870, estallaba la guerra franco-prusiana, el conflicto europeo que marcó la agenda política de dos de las principales potencias en el continente. La importancia de este contexto bélico para la historia de la tarjeta postal resulta indiscutible, ya que la propia contienda tuvo repercusiones directas en la puesta en marcha del nuevo formato, tanto en territorio germano como galo.

El 6 de junio de 1870, todavía en los momentos previos al inicio de las hostilidades, el canciller Otto von Bismarck firmaba el Verordnung betreffend die Einführung der Correspondenzkarte (Reglamento sobre la introducción de la tarjeta de correspondencia), que entraría en vigor el 1 de julio. Al igual que se había hecho un año antes en el Imperio austrohúngaro, Bismarck proporcionó en un detallado texto las directrices relativas a la forma de uso, los procedimientos de envío y las distintas tarifas vigentes.

La parte frontal de la tarjeta de correspondencia contiene un formulario destinado a la dirección. El reverso se puede utilizar en su totalidad para mensajes escritos. La dirección y el mensaje pueden escribirse con tinta, lápiz, lápiz rojo u otro material para colorear, la escritura debe cumplir y ser clara. Los mensajes en la parte posterior también se pueden hacer mediante impresión, litografía, etc., y se permiten subsecciones escritas. Los formularios

3 En el siguiente enlace de la Österreichische Nationalbibliothek se puede localizar el correspondiente artículo publicado el 26 de enero de $1869 \mathrm{http} / /$ anno.onb.ac.at/cgicontent/anno?aid $=$ nfp\&datum $=18690126 \&$ seite $=4 \& z o o m=33$ [Consulta: $25-11-2020$ ]. 
para las tarjetas de correspondencia se pueden obtener en todas las oficinas de correos, así como a través de los carteros. Estos ya están franqueados con la tarifa para el transporte que representa el sello de 1 Groschen, o 3 Kreuzer [...]. Las disposiciones anteriores entrarán en vigor el 1 de julio de $1870^{4}$.

De esta manera, el nuevo contexto bélico se posicionaba como el momento idóneo para que tuviera lugar la puesta de largo del recién estrenado formato, el cual tenía la importante tarea de demostrar su valía. Desde los primeros días, la postal contó con un considerable ámbito de actuación, sobre todo gracias a iniciativas como la distribución de ejemplares gratuitos entre el frente y la retaguardia que permitían aproximar ambos escenarios. Además, la amplia difusión que se le dio al novedoso soporte hizo que la población se familiarizara rápidamente con él y que, una vez concluidas las hostilidades, gozara de especial popularidad. Según se ha podido comprobar durante la consulta de los ejemplares, algunos de los mensajes más repetidos fueron "sigo vivo" o "estoy bien", siempre escritos muy breves orientados a tranquilizar a todos aquellos familiares que seguían con incertidumbre el avance de la guerra.

En esos mismos días August Schwartz, un afamado librero alemán, escribió a su suegro desde Oldemburgo a Magdeburgo para informarle del estallido de la guerra. Esta iniciativa le llevó a decorar la esquina superior izquierda de la tarjeta con un pequeño dibujo de un artillero junto a un cañón, en alusión al clima bélico que se había instalado y que él mismo describe en el mensaje como "la salvaje agitación de la guerra" 5 . Precisamente, el hecho de enviar el ejemplar acompañado del citado diseño ha sido un motivo de peso para que no pocos autores hayan situado a Schwartz como el precursor de la tarjeta postal ilustrada (véase figura 1). De esta manera, ya desde sus inicios se detecta cómo en el seno de un conflicto armado fue donde se dieron los primeros pasos

\footnotetext{
4 Texto traducido por el autor a partir del original en alemán: Amtsblatt der Königlichen Regierung zu Potsdam und der Stadt Berlin, 24 de junio de 1870, accesible en el siguiente enlace http://books.google.de/books?id=ClQNAAAAIAAJ [Consulta: 27-11-2020].

5 Traducción propia de la expresión en alemán "wilden Kriegsgetümmel", utilizada por Schwartz al inicio del mensaje.
} 
relativos a la ilustración de las tarjetas y a la producción privada (Philippen, 1977, p. 27).

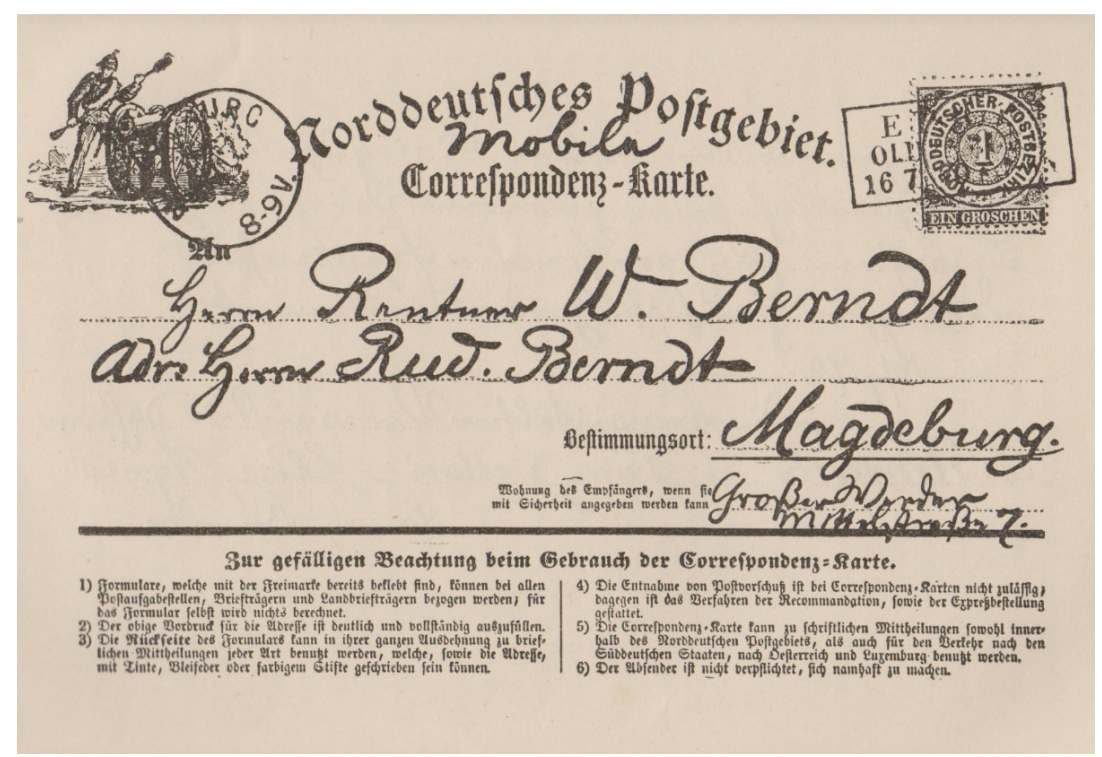

F1. Postal enviada por Schwartz, 1870. Wikimedia Commons.

Una situación similar es la que se vivió en la vecina Francia, inmersa por igual en el conflicto europeo y donde la postal tuvo su implantación con motivo del propio desarrollo de la guerra. El hecho decisivo fue el asedio que sufrió la ciudad de Estrasburgo entre agosto y septiembre de 1870 a manos de las tropas del general August von Werder. En ese tiempo la Sociedad de Socorro para los soldados heridos de los ejércitos de tierra y de mar solicitó a los altos mandos prusianos que permitieran a los asediados poder comunicarse con sus familiares en el exterior. Ellos aceptaron hacerlo a través de tarjetas postales con la condición de que llevaran sello alemán y de que pasaran por Karlsruhe y Basilea para así ejercer un control eficaz de la información que circulaba (Ripert \& Frère, 2001, p. 17). Su diseño era muy sencillo, ya que contaba únicamente con unas pocas líneas para la redacción del mensaje y la dirección de destino, una cruz roja en la parte superior y la inscripción Société de secours aux blessés militaires des armées de terre et de mer - Comité Auxiliaire de Strasbourg. 
Junto a este ejemplo de la ciudad de Estrasburgo, encontramos otra referencia ampliamente conocida, aunque no exenta de debate dentro del mundo académico, que también atañe a la circulación de postales en suelo francés en el tiempo de duración de la guerra. Ante la amenaza prusiana y con el fin de reorganizar al ejército, se decidió establecer un campamento en las proximidades de Le Mans, desde donde se pretendía continuar después el avance. No muy lejos de ese asentamiento, en la pequeña localidad de Sillé-leGuillaume, residía Léon Besnardeau, un librero local que regentaba desde hacía varias décadas su propio negocio. El hecho discutido viene a raíz de un artículo publicado el 6 de septiembre de 1902 en el Petit Journal donde se dice que habría tenido la idea de crear una postal con el fin de que los soldados del campamento de Conlie pudieran contactar con sus familias:

Le dio la idea de crear, para las tropas del campo, un medio de correspondencia simplificado por la supresión de la envoltura. Contrariamente al uso adoptado para las tarjetas actuales, la ilustración, limitada a los atributos militares: fasces, cañones, proyectiles, se completa con la indicación: Camp de Conlie, con un lugar para la dirección y se encontraba en el anverso. El reverso, reglado, estaba reservado para texto $[\ldots]^{6}$.

Sin embargo, tal y como señala Jos Philippen (2001, p. 19), por el momento no se conoce ningún ejemplar que fuese franqueado durante el periodo de las operaciones de guerra, solo en años posteriores. Por este motivo, a pesar de haber situado largo tiempo el ejemplo de Besnardeau como uno de los primeros intentos de circulación de postales en Francia, cada vez son más los que se decantan por la solución de que fueran distribuidos como souvenir o recuerdo del lugar donde había estado instalado el asentamiento y no propiamente como correspondencia bélica.

Frente a la sencillez de las postales de Schwartz, los dos modelos diseñados por Besnardeau presentan una mayor ornamentación. El primero de ellos muestra elementos bélicos colocados en disposición piramidal y rematados

${ }^{6}$ Traducción del autor realizada a partir del texto original en francés. Ejemplar digitalizado disponible en el siguiente enlace: https://gallica.bnf.fr/ark:/12148/bpt6k616184p.item [Consulta: 14-11-2020]. 
por dos coronas vegetales en cuyo interior encontramos alusiones a todo aquello que los soldados estaban llamados a defender: patria, familia, honor y libertad7. Por su parte, el segundo contiene una gruesa guirnalda vegetal que rodea toda la cartulina con abundantes motivos. En torno a ella se distinguen las palabras Famille, Honneur, Patrie y Liberté y dos cañones entrecruzados sobre unas banderas en la parte inferior. La banderola que preside el lado superior lleva la inscripción Guerre 1870-71, Souvenir de la défense nationale, algo que da alas a la interpretación expuesta anteriormente.

Aun así, hubo que esperar hasta finales de 1872 para que se debatiera sobre la necesidad de introducir de manera oficial la postal en Francia, proceso que podemos conocer gracias a la información publicada en el Journal officiel de la République Française del 20 de diciembre de $1872^{8}$.

Como se ha podido apreciar, la década de 1870 fue trascendental para la implantación del nuevo soporte y para comprobar las ventajas que podría ofrecer como medio de comunicación dentro del contexto de la guerra. Pasados estos primeros años, las dos décadas siguientes fueron decisivas para el despegue del soporte y la popularidad de la tarjeta postal creció a un ritmo cada vez más acelerado. En consonancia, se debieron ir tomando las medidas necesarias que condujeran al completo despegue del formato. Uno de los pasos decisivos fue la creación en 1874 de la Unión Postal General, posteriormente denominada Unión Postal Universal (UPU), ya que permitió el traspaso de fronteras e hizo que la tarjeta viajara por todo el mundo. Por otro lado, la celebración de las Exposiciones Internacionales propició el verdadero nacimiento de la postal ilustrada, cuyo desarrollo acabó por situar estas pequeñas cartulinas a la cabeza de los envíos en los buzones de todo el globo y las convirtieron en objetos codiciados por el gran público. En definitiva, fueron avances que permitieron catapultar a la postal hasta lo más alto y la

\footnotetext{
7 En el siguiente enlace del Musée de Bretagne se puede visualizar un facsímil editado en 1902 del ejemplar en cuestión: http://www.collections.museebretagne.fr/ark:/83011/FLMjo239057 [Consulta: 26-11-2020].

8 Documento completo disponible en el siguiente enlace: https://gallica.bnf.fr/ark:/12148/bpt6k6209159f?rk=21459;2 [Consulta: 26-11-2020].
} 
prepararon para vivir su edad de oro al calor del nuevo siglo (Lara \& Martínez, 2009, p. 65).

\section{La edad de oro de la postal y la Gran Guerra (1898-1918)}

En aquellos años dorados la tarjeta ilustrada se convirtió en un verdadero negocio y en torno a ella se crearon grandes empresas dedicadas a su fabricación, edición y venta. Podemos afirmar que se estableció toda una industria al servicio de la postal, un entramado que trataba de satisfacer una demanda cada vez mayor y más exigente (Sánchez \& Villena, 2010, p. 39). Entre la extensa gama de tarjetas con las que se podía encontrar el público, las ilustradas con fotografías fueron las más demandadas. Los fotógrafos, conocedores del éxito de este mercado, encontraron en ellas una vía complementaria de trabajo y fueron muchos los que reproducían sus obras sobre este soporte con el fin de ver incrementadas sus ventas. El repertorio de temas cubiertos fue amplísimo: arte, catástrofes, desnudos, avances tecnológicos, ciudades, paisajes, monumentos, vida cotidiana y así una interminable lista de motivos (Riego, 2011, p. 11 y Ripert \& Frère, 2001, p. 79).

Del mismo modo, la guerra también consiguió llegar a la ilustración de las tarjetas y con el cambio de siglo se incorporó de lleno a su elenco temático. A pesar de que ya había estado presente dentro del mundo bélico desde sus mismos orígenes, los usos que se le van a conceder en los enfrentamientos armados de la nueva centuria y la dimensión de su producción supondrán una completa novedad. Si bien en la guerra franco-prusiana había funcionado únicamente como medio de comunicación interpersonal, durante los siguientes enfrentamientos armados se perfilará como uno de los canales más eficaces de propaganda y será ampliamente utilizada por las naciones implicadas como vector de información (May, 2012).

Uno de los primeros momentos en los que se puso en práctica este nuevo uso fue en la Segunda Guerra Bóer (1899-1902). La producción británica dedicó amplios recursos a la edición de tarjetas durante el conflicto y los ejemplares más significativos son aquellos ilustrados con consignas patrióticas que 
buscaban ensalzar la fuerza de la nación ante el escenario de amenaza que se les presentaba: banderas, estandartes portados por soldados, imágenes de la reina Victoria o símbolos nacionales como el bulldog (Cowlin, 2014).

Además de esos motivos, algunos de los episodios de la contienda también tuvieron una presencia destacada en los anversos de las postales, como por ejemplo el asedio de Ladysmith. Entre el mes de noviembre de 1899 y febrero de 1900 los bóeres sitiaron dicha localidad, que permanecía bajo control británico, y las comunicaciones quedaron totalmente suspendidas. Los dirigentes ingleses supieron utilizar la tensa situación vivida en suelo africano y rápidamente la prensa internacional se hizo eco de tal episodio. Del mismo modo, fueron varias las tarjetas editadas con motivos referentes al asedio como planos de la villa y de sus alrededores o diferentes representaciones alegóricas femeninas de Ladysmith, recursos que convirtieron este suceso en un verdadero símbolo de la guerra. Por su parte, en Bélgica, Francia, Alemania u Holanda se editaron tarjetas de propaganda antibritánica en las que se ensalzaba la actividad de los bóeres y se denigraba la actitud imperialista mantenida desde Londres. Con todo este material, Europa se convertía en el escenario de las disputas surgidas en torno a una contienda desarrollada a miles de kilómetros de distancia9.

Apenas unos años después de que finalizara la Segunda Guerra Bóer, comenzaba otra contienda, en el extremo opuesto del globo, entre la Rusia zarista y el Imperio japonés. Las propias características del nuevo conflicto atrajeron la atención de las potencias europeas, ya que representaba una lucha entre Oriente y Occidente. Para el mundo de la postal, el ataque del almirante Tōgō sobre Port Arthur el 8 de febrero de 1904 provocó un interés inusitado tanto en las casas editoras de las dos potencias implicadas como en la de otros tantos países. Las continuas tarjetas producidas consiguieron hacer de la guerra un auténtico espectáculo contemplado por millones de personas y su éxito se debió, en buena medida, a la decisión de redactar en varios idiomas

9 Véase una breve muestra de ejemplares editados durante el conflicto en el siguiente enlace: https://www.historyworkshop.org.uk/radical-objects-boer-war-postcards/ [Consulta: 26-112020]. 
los mensajes del anverso. Los editores rusos y japoneses eran conscientes de la cobertura internacional que conseguirían, por lo que recurrieron a ejemplares bilingües que presentaban la información en la lengua nativa e inglés, tarjetas trilingües (inglés, francés y alemán) o bien con títulos hasta en siete idiomas (Carlson, 2009).

Desde el punto de vista temático, los motivos elegidos en ambos países presentaron unas características semejantes. Por un lado, las tarjetas ilustradas con fotografías mostraron de manera directa el avance de la contienda y proyectaron al mundo entero el conflicto librado en Oriente. Las escenas más repetidas corresponden al ataque a Port Arthur, el desembarco japonés en Chemulpo, la batalla del Mar Amarillo o la de Liaoyang. Por su parte, la caricatura también jugó un papel importante y fue utilizada para desprestigiar al enemigo. De manera general, los rusos eran representados como gigantes torpes con pobladas barbas y costumbres toscas y los japoneses eran caracterizados como enemigos minúsculos fácilmente abatibles pero llenos de codicia. Los países europeos también estuvieron presentes en las tarjetas editadas por ambos contendientes, ya que los coloridos diseños celebraban las alianzas firmadas. Por último, en esos mismos territorios también se editaron tarjetas en apoyo de uno u otro bando, ejemplares que completaron el amplio abanico de los que disponemos acerca de ese conflicto (O'Connor \& Cohen, 2001).

En definitiva, se ha podido constatar cómo estos primeros conflictos librados en el siglo XX permitieron a la postal mostrar sus diversas facetas en el seno del contexto bélico más allá de su uso como medio de comunicación interpersonal. Sin embargo, su gran despegue llegaría con el estallido de la Gran Guerra, el momento de mayor circulación de tarjetas en el viejo continente.

Durante los años que duró el conflicto, algunos países europeos vivieron un auténtico frenesí en los envíos de correo y se alcanzaron cifras muy superiores a cualquier periodo anterior. El holandés Guus de Vries (2016, p. 16) afirma que en Alemania fueron cerca de 16,7 millones los envíos transportados a diario entre los varios frentes y el territorio nacional, mientras que en Francia 
eran alrededor de 4 millones cada jornada. Con estos números, calcula que, en Alemania, Gran Bretaña y Francia durante la guerra se distribuirían alrededor de 45 mil millones de piezas postales que, sumado a los 10 mil millones de Rusia y Austria-Hungría llegaría a la cifra total de 60 mil millones, de los que la mitad eran postales. Con esto concluye que fueron alrededor de 30 mil millones de tarjetas las que se enviaron y recibieron entre agosto de $1914 \mathrm{y}$ noviembre de 1918.

Estos números no se explican si no se presta atención al propio contexto propiciado por la movilización masiva de millones de personas. Separados de sus familias por miles de kilómetros, los soldados que participaron en la Gran Guerra hicieron todo lo posible para comunicarse con sus seres queridos. Los dirigentes militares rápidamente fueron conscientes de la influencia tan decisiva que el correo tenía en la moral de las tropas, por lo que hicieron todo lo posible con el fin de incentivar su utilización entre los combatientes. A esto se le suman otras ventajas como la brevedad del mensaje, que hacía de estas pequeñas cartulinas un medio mucho más adecuado para una guerra en la que las posiciones cambiaban con relativa frecuencia, y el hecho de mantener el mensaje al descubierto, que facilitaba en gran medida la censura o el control de la información que circulaba (Vries, 2016, p. 9).

La legislación que regulaba el uso del soporte no se hizo esperar y, apenas unos días después de que dieran comienzo las hostilidades, la mayor parte de los países implicados en la contienda publicaron las directrices que regularían la circulación de las postales en el periodo de guerra. Por ejemplo, en Francia, el 3 de agosto de 1914 se publicó el decreto concerniente a la franquicia militar, donde se indicaba que todos los envíos debían ser inferiores a 20 gramos de peso y se establecía la gratuidad de envíos del frente a la retaguardia para asegurar el contacto de todos aquellos hombres movilizados ${ }^{10}$. Unos días más tarde, el 19 de agosto, se publicaba otra orden por la que se autorizaba la emisión de dos modelos de tarjetas oficiales catalogados con las letras A y B. A

${ }^{10}$ Información completa en el Bulletin mensuel des postes et télégraphes, 10 (1914), pp. 325366, disponible en el siguiente enlace https://gallica.bnf.fr/ark:/12148/bpt6k5522630k/f23.image.texteImage [Consulta: 25-112020]. 
su vez, de cada modelo se editaron distintos diseños, todos ellos ilustrados con pequeñas banderas de los países que combatían del lado de Francia. En el transcurso de la investigación en instituciones francesas se han localizado 8 variantes del tipo A y 2 del tipo B de esta primera remesa. Tal y como se explica en la propia normativa:

El modelo A está destinado a la correspondencia enviada por militares y marineros. Las tarjetas de este modelo se ponen a disposición de las tropas de forma gratuita por el servicio del Tesoro y Correos a los ejércitos. Las tarjetas del modelo B son para uso privado para correspondencia destinadas a los militares y marineros. Se ponen a la venta al precio de 2 francos el paquete de diez, en todas las oficinas de correos, servicios auxiliares y estancos ${ }^{11}$.

Como hemos tenido oportunidad de comprobar, la tarjeta postal ya había demostrado sus cualidades como medio de comunicación dentro de escenarios bélicos, por lo que la Gran Guerra no introdujo una completa novedad a este respecto. Lo que sí supuso un hecho singular fue la escala con la que se utilizó y el uso masivo que se hizo de ella, a lo que también contribuyó sin duda la función como vector de propaganda que se le confirió en este momento. Si bien fue en las contiendas descritas anteriormente cuando comenzó de manera tímida a perfilarse como tal, sería en 1914 cuando realmente experimentó un desarrollo exponencial (López-Torán, 2017, p. 291).

En efecto, los organismos encargados de la propaganda estatal en los diferentes países implicados rápidamente encontraron en este soporte un medio de difusión excelente que cumplió a la perfección con su tarea, sobre todo gracias al empleo de la caricatura y a los amplios reportajes fotográficos que se realizaron para ilustrar sus anversos. Así, se convirtieron en potentes mecanismos de transmisión de ideas y en un medio privilegiado para aproximar a la población a la realidad del conflicto, tanto en aquellas naciones que se vieron implicadas de manera directa en el enfrentamiento, como en las que mantuvieron una posición oficial de neutralidad, pero a las que

\footnotetext{
${ }^{11}$ Texto íntegro disponible en Bulletin mensuel des postes et télégraphes, 10 (1914), pp. 328, https://gallica.bnf.fr/ark:/12148/bpt6k552263ok/f26.image.texteImage [Consulta: 25-112020].
} 
inevitablemente también llegaron un buen número de ejemplares relativos a la contienda (Bürgschwentner, 2013 y Delhalle, 2011) ${ }^{12}$.

Entre los mayores conjuntos que se han localizado merece la pena señalar escenas de campos de batalla, imágenes de tropas realizando todo tipo de actividades (véase figura 2), fotografías del nuevo armamento utilizado en la contienda y vistas de un sinfín de localidades destruidas. Por su parte, la caricatura fue utilizada para atacar al enemigo de manera despiadada y para contribuir a ensalzar los valores nacionales, para lo que recurrieron a todo tipo de recursos (Schulze, 2013, p. 22).

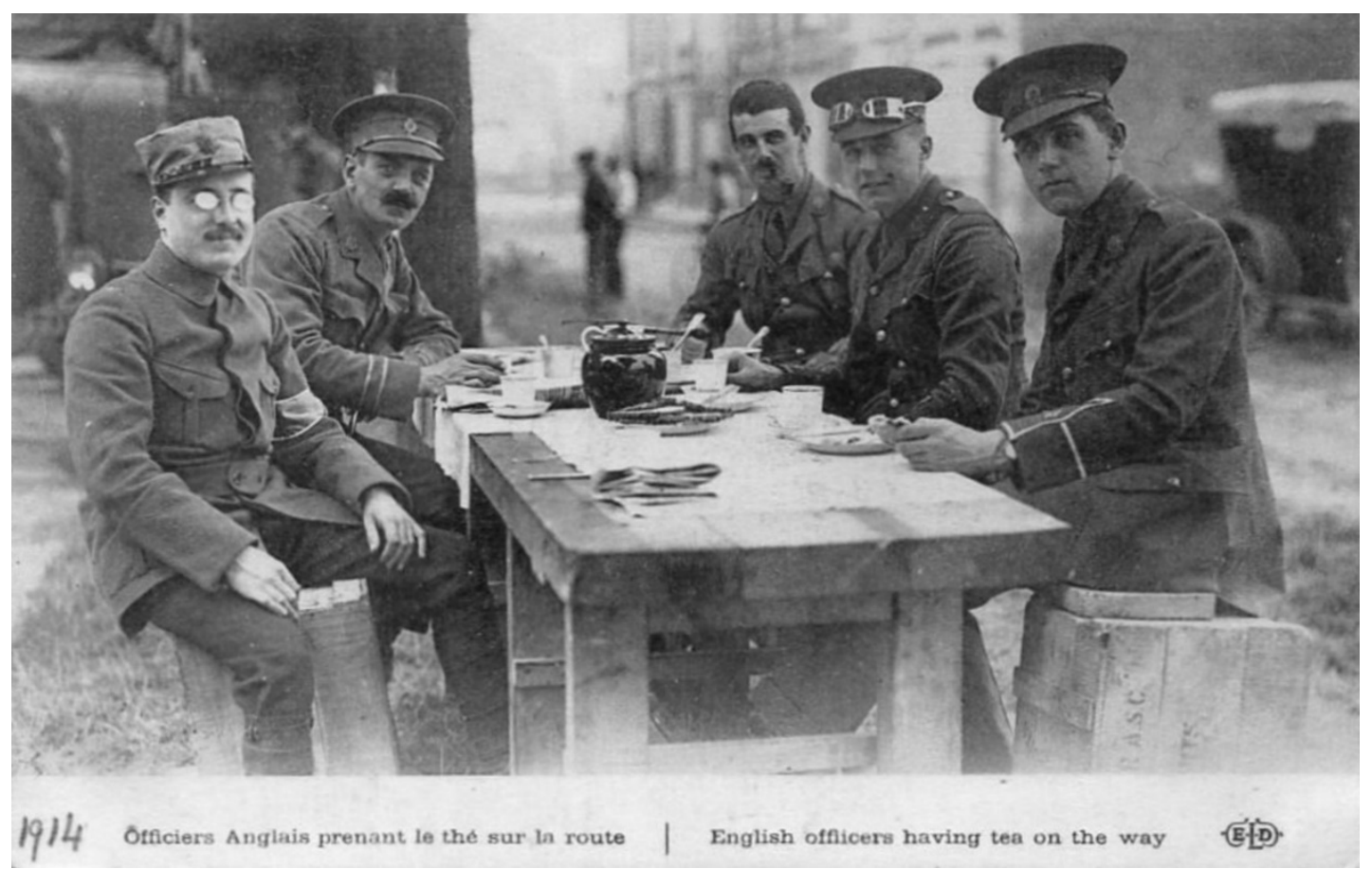

F2. Officiers anglais prenant le thé sur la route, 1914. Colección José Manuel López Torán.

Los altos niveles de circulación mencionados se mantuvieron más o menos constantes en los cuatro años de duración del conflicto en prácticamente todos los países europeos, si bien es cierto que en los últimos meses se detecta una leve disminución debido a las complicaciones derivadas del avance de las hostilidades. Sin embargo, con el fin de la guerra llegó también el ocaso de la

${ }_{12}$ De los muchos proyectos de digitalización que se han llevado a cabo en torno a la postal de la Gran Guerra, merece la pena destacar Europeana 1914-1918 debido a su envergadura y alcance. En su portal web se pueden visualizar miles de ejemplares con las características descritas en el texto: http://www.europeana1914-1918.eu/en/explore [Consulta: 2-12-2020]. 
edad de oro para la tarjeta postal. La calidad no era la misma, los temas elegidos para la ilustración tampoco y, finalmente, las cifras de envíos, el único factor que nos permitiría alargar unos años más esa etapa dorada, experimentaron su derrumbe al concluir la contienda.

\section{La postal de entreguerras: el lento camino hacia el declive (1920- 1945)}

A partir de 1920, seguir de cerca la evolución del formato de una manera más o menos uniforme, como había ocurrido en los periodos anteriores, resulta sin duda una tarea de mayor complejidad. Uno de los principales motivos es la situación tan diferente por la que fueron atravesando los países europeos en las décadas de los veinte y los treinta, sobre todo en lo que respecta a la evolución de sus sistemas políticos y socioeconómicos. Aun así, es posible detectar elementos de unión en la relación de la postal con la guerra y en lo concerniente a su presencia en el seno de los enfrentamientos armados que se fueron sucediendo.

Uno de esos puntos comunes lo encontramos en la presencia que siguió teniendo la contienda finalizada en 1918 entre la población europea y en el imaginario colectivo. La profunda huella que dejó el trágico enfrentamiento armado tuvo su repercusión en el mundo de la postal durante tiempo y los motivos bélicos siguieron copando buena parte de los ejemplares editados o circulados en los años posteriores ${ }^{13}$.

Además del recuerdo de la Primera Guerra Mundial, no debemos olvidar que, en esta década, algunos países europeos se vieron implicados en nuevos conflictos bélicos, de mucha menor escala, pero que nuevamente rescataron a la postal como medio de comunicación interpersonal y como vector de propaganda. Uno de los casos más significativos lo encontramos precisamente en España con la guerra de Marruecos, donde asistimos a un repunte en el

${ }_{13}$ Por ejemplo, en el War Heritage Institute de Bruselas se han localizado varios ejemplares circulados en los años 1921, 1924, 1926, 1930 o 1931 ilustrados todavía con motivos bélicos de la Gran Guerra. 
número de personas desplazadas lejos de sus hogares. Entre las medidas más destacadas que afectaron al mundo de la correspondencia destaca la propuesta del entonces ministro de Hacienda, Francisco Cambó y Batlle, de crear una tarjeta sencilla para los soldados movilizados en África y otra doble o con respuesta pagada para ser enviada por los familiares desde la Península, Baleares o Canarias ${ }^{14}$. Además de estos ejemplares oficiales, de diseño mucho más sencillo, encontramos otras muchas ilustradas tarjetas con imágenes de las distintas campañas y que recuerdan plenamente a la estética de las postales de la Gran Guerra. Soldados, ruinas, armamento y los numerosos campamentos establecidos fueron nuevamente algunos de los motivos elegidos para ilustrar las cartulinas durante el tiempo que duraron las operaciones en el norte de África.

En esos mismos años, el continente europeo se veía cada vez más amenazado por la sombra del fascismo. Este mismo avance cubrió también la producción de la postal y con la caída progresiva de las democracias y la instauración de regímenes autoritarios o totalitarios este formato fue adoptando unas características nuevas. El Tercer Reich pronto se configuró como un verdadero imperio militar y, al ritmo de los fastuosos desfiles, las tropas de Hitler y el partido nazi fueron copando todos y cada uno de los espacios de la vida pública. Esa omnipresencia vino acompañada de una intensa campaña propagandística perfectamente organizada desde la cúpula nazi y dentro de ella la postal fue elegida como uno de los mejores canales para transmitir las ideas. De esta manera, Alemania se convirtió durante este periodo en el paradigma de la utilización de las tarjetas ilustradas como elemento de propaganda política, ya que los ejemplares editados sobrepasaron con creces los de otros territorios debido, sobre todo, a esa función que se le proporcionó. De nuevo, la originalidad de su ilustración quedó relegada a la mínima expresión al posicionarse completamente al servicio del nuevo régimen y de la nueva visión que la doctrina nazi implantó (Moore, 2003).

14 Gaceta de Madrid: núm. 256, de 13/09/1921, p. 1034. Texto completo disponible en el siguiente enlace: https://www.boe.es/datos/pdfs/BOE//1921/256/A01034-01034.pdf [Consulta: 4-12-2020]. 
A la vista de los numerosos ejemplares consultados, el rostro del Führer se convirtió en el motivo predilecto para los anversos, así como el poderío militar y armamentístico que durante la década fue adquiriendo el país. Estos dos casos reflejaban a la perfección la imagen que el nuevo orden nazi quería transmitir y, junto a ellos, toda una serie de consignas trasladadas desde el partido terminaron por eclipsar cualquier otro intento de producción. De manera general, esos motivos pueden quedar resumidos en la idea de trabajar y aunar esfuerzos para construir una nación fuerte, una nueva Alemania que tomara el relevo de los periodos más gloriosos de su dilatada historia y que combatiera la humillación a la que fue sometida por las duras condiciones expuestas en los tratados de 1919. Ese camino solo sería posible de la mano de Hitler, el gran protector de la patria y el elegido para situar al país en la cumbre de la civilización, tal y como se puede leer en los anversos de multitud de ejemplares.

Del mismo modo, en los años treinta la postal italiana fue testigo de la evolución política del país. Aunque se ha podido detectar una incidencia mucho menor, sí que es notorio cómo la influencia del Partito Nazionale Fascista se fue haciendo latente en todos los aspectos de la vida cotidiana y, por extensión, también en la tarjeta postal. Al igual que en Alemania, el culto al líder fue uno de los motivos más recurrentes y se cuentan por centenares los ejemplares editados durante esta década dedicados a la figura del Duce (Sturani, 2003).

A tenor de lo planteado, podemos afirmar que los distintos cauces políticos que siguieron las naciones europeas también tuvieron sus efectos en lo que respecta al volumen de producción, lo que nos lleva a exponer la teoría de que, en el periodo de entreguerras, se mantuvieron niveles superiores de edición en los territorios cuyos regímenes desplegaron intensas campañas de propaganda. En Alemania e Italia esas cifras se vieron acrecentadas por los propios rasgos militares de sus regímenes políticos y en España, ante todo, por el inicio en 1936 de un nuevo conflicto armado.

En efecto, la guerra civil librada entre 1936 y 1939 llevó a la postal a contar, una vez más, con niveles elevados de producción y circulación. Una vez más, 
la movilización de centenares de miles de personas motivó la necesidad de acudir a la correspondencia para mantener el contacto y, al igual que se había realizado en la Gran Guerra, pocas son las tarjetas que no fueron aprovechadas por los contendientes para incluir consignas propagandísticas sobre su causa. Nuevamente, resulta conveniente recurrir a la legislación para seguir la pista del papel que jugó la postal dentro del conflicto bélico. Así, por ejemplo, el 8 de agosto de 1936 se ordenaba en el bando republicano "organizar adecuadamente el servicio postal” con el fin de que los soldados pudieran "cambiar con sus familiares para satisfacer sus necesidades, su comodidad o regalo" 15 .

El desarrollo de la guerra y el avance de Franco obligó a la República a seguir tomando medidas referentes a la comunicación postal. Así, el 30 de octubre de 1936 ante "la conveniencia de sustraer a la infancia del ambiente bélico que la proximidad de la lucha produce" se aconsejó "evacuar a zonas alejadas de la contienda a numerosos niños que tienen su habitual residencia en las afectadas hoy por el curso de las operaciones". Así, entró en vigor una iniciativa sin precedentes y de gran calado que contemplaba la gratuidad de los envíos para esos niños evacuados ${ }^{16}$.

Por su parte, en el territorio dominado por el bando franquista, la postal contó con una situación de mayor precariedad durante los primeros meses de la guerra, ya que los principales centros de producción seguían controlados por la República. En lo que respecta a la legislación dentro de este bando, el día 17 de noviembre de 1937 se publicaban las directrices oportunas y se concedía la franquicia postal al Servicio de Información y Asistencia a Frentes y Hospitales ${ }^{17}$.

Por lo que respecta a la ilustración de los ejemplares, en el bando franquista, se ha podido apreciar cómo la exaltación de los principales dirigentes fue uno

\footnotetext{
15 Fragmento extraído de https://www.boe.es/datos/pdfs/BOE//1936/221/Bo1141-o1141.pdf [Consulta: 30-11-2020].

${ }_{16}$ Texto completo en https://www.boe.es/datos/pdfs/BOE//1936/304/Boo550-00550.pdf [Consulta: 30-11-2020].

17Véase el texto en https://www.boe.es/datos/pdfs/BOE//1937/395/A04410-04413.pdf [Consulta: 30-11-2020].
} 
de los asuntos más recurrente para ser recogidos en los anversos. Sin lugar a duda, la imagen de Franco fue, de lejos, la más repetida. Según las estimaciones de Ricard Martí (2000, p. 113 y 133), se cifra en más de doscientos ejemplares diferentes los que fueron dedicados a su figura, lo que supone cerca del $20 \%$ del total de los modelos editados por los sublevados. Junto a él, Queipo de Llano, Yagüe, Moscardó, Sanjurjo o Serrano Suñer tuvieron su lugar dentro de las postales de la guerra civil.

A la par, los propios acontecimientos fueron utilizados para ilustrar los anversos de las tarjetas y, por ejemplo, el asedio y la defensa de Madrid fueron motivos que produjeron algunas de las series más extensas de toda la guerra civil. Muchas organizaciones editaron numerosas postales con consignas para ayudar a los niños de los bombardeos o, por supuesto, con imágenes que ilustraran las ciudades arrasadas y dieran muestra de la destrucción que estaba acarreando la guerra.

Finalmente merece la pena señalar los ejemplares editados en distintos países europeos y que tenían como destino la contienda española. Así, desde Alemania e Italia llegaron postales cuyos temas centrales eran la alineación de las dos naciones con Franco y la participación de la Legión Cóndor o del Corpo di Truppe Volontarie, mientras que Francia hizo lo propio con el bando republicano. De entre estas últimas destacan las series La révolution du front populaire en Espagne, Evenéments d'Espagne y L'exode espagnole dans les Pyrenées Orientales ${ }^{18}$, todas ellas relativas a las campañas en las zonas más próximas al territorio francés (véase F3).

\footnotetext{
${ }_{18}$ El Centro de Estudios de Castilla-La Mancha ha puesto a disposición del público 32 ejemplares de la serie L'exode espagnole dans les Pyrenées Orientales a través de su cuenta de Flickr: https://www.flickr.com/photos/ceclm/sets/72157632045681233/ [Consulta: 2311-2020].
} 


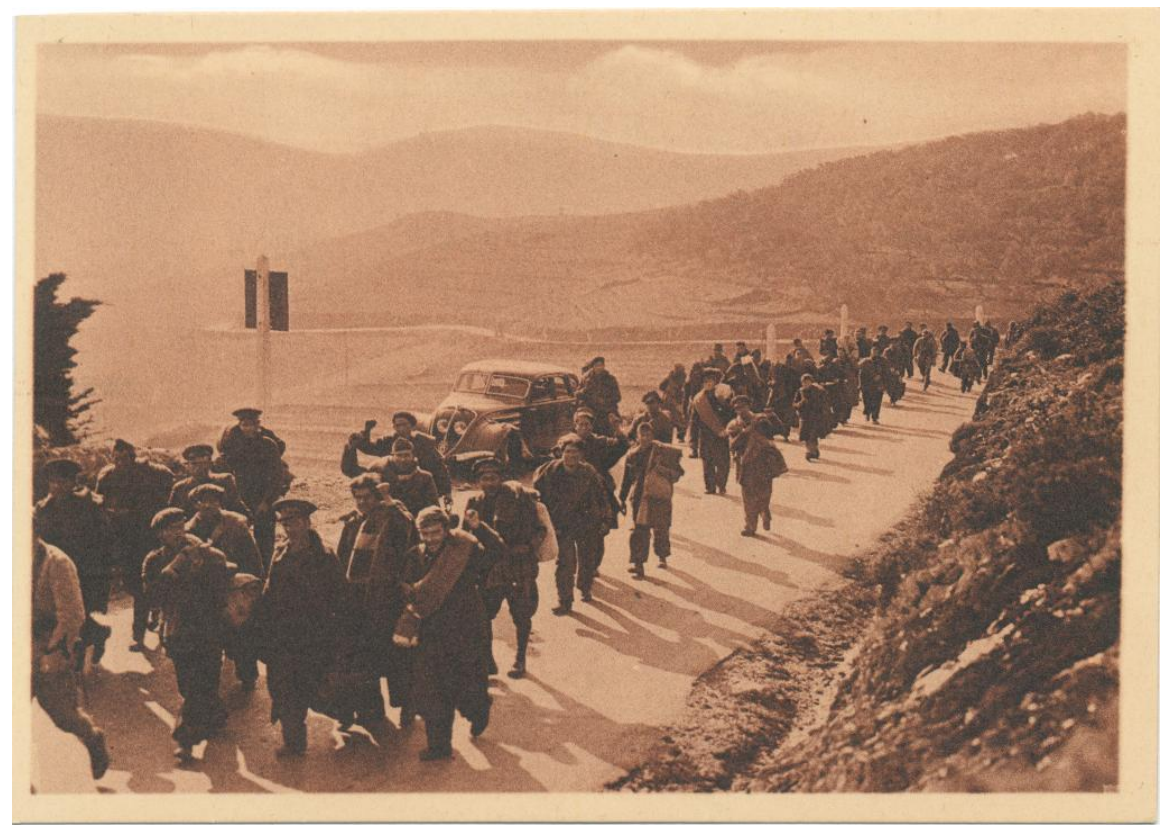

F3. Sur la route de Banyuls: Miliciens se dirigeant sur Argelés, 1939. (C) Centro de Estudios de Castilla-La Mancha.

España se convertía así en el campo de operaciones de la propaganda europea, donde la postal se posicionó como uno de los medios preferidos para las agencias internacionales encargadas de dicho cometido. A la par, los ejemplares circulados por la península ibérica fueron el antecedente inmediato del siguiente conflicto bélico mundial que estallaría apenas unos meses después de que finalizara la Guera Civil.

El rumbo que habían ido tomando los acontecimientos en la Europa de los años treinta hacía presagiar que, tarde o temprano, los peores temores se cumplirían, ya que la sombra de un nuevo conflicto en el continente era cada vez más alargada. Cuando el 1 de septiembre de 1939 estallaba la Segunda Guerra Mundial, la comunicación entre todos esos individuos era, nuevamente, una tarea indispensable para ellos mismos y necesaria para los gobiernos implicados, que ya contaban con la experiencia acumulada de los conflictos bélicos previos y conocían los efectos positivos que conllevaba. En esencia, las características fueron muy similares a las descritas anteriormente y en la mayor parte de los casos recurrieron a las estrategias que habían resultado exitosas en la Gran Guerra. No obstante, resultaba inevitable introducir nuevos adelantos que adecuarán el soporte a la nueva realidad en la que se desarrollarían las hostilidades, por lo que también se han detectado 
rasgos característicos que van a diferenciar ligeramente los ejemplares editados y distribuidos a partir de 1939 (Holt \& Holt, 1987, p. 8).

Una de las diferencias más claras la encontramos en el volumen de producción y de envío ante las oportunidades que ofrecían los nuevos medios de comunicación. A pesar de que las necesidades de producir campañas propagandísticas económicas y de fácil difusión reavivaron el uso de la postal en todas las naciones involucradas, su volumen fue notablemente menor que en la Gran Guerra. Es preciso señalar que, mientras que el estallido de la contienda en 1914 coincidió con el periodo dorado de la postal, en este momento nuevas formas de transmisión de información habían desplazado a las tarjetas a un segundo plano. La radio había ganado un protagonismo indiscutible en el terreno de la propaganda, tanto en la Alemania de Goebbels como en las potencias occidentales. Por otro lado, los carteles seguían inundando las calles, los folletos hacían lo propio en los territorios controlados por el enemigo y el cine se erigió como un medio formidable. Aun así, la postal tuvo la oportunidad de demostrar una vez más que sus propias características la hacían funcionar a la perfección como medio de comunicación interpersonal en escenarios bélicos, incluso con las continuas dificultades que se le iban interponiendo.

En lo que respecta al elenco de temas al que recurrieron para ilustrar los anversos, es preciso indicar que su variedad estuvo condicionada por la dispar situación en la que se encontraron cada una de las potencias implicadas en la contienda. Por ejemplo, en el Reino Unido utilizaron estrategias muy similares a las de la Gran Guerra y de nuevo los motivos patrióticos, las fotografías del frente y las alusiones al esfuerzo nacional coparon una amplia cuota de la producción. En este sentido, se ha detectado que se trata de uno de los territorios que presentan una mayor continuidad entre los dos conflictos mundiales. Por su parte, en Alemania el soporte quedó sometido por completo a la sombra del nazismo y heredó todos los rasgos que había adoptado desde el ascenso al poder de Hitler en 1933. Finalmente, un país que resulta interesante es Francia ya que, al quedar parte de su territorio ocupado entre 1940 y 1944, se produjo una fuerte disparidad en la producción en una y otra 
zona (Holt \& Holt, 1987, p. 9). En el norte del país, las tarjetas producidas cuentan con una clara influencia germana, aunque los mensajes y títulos se redactaron en francés con el fin de facilitar su comprensión. Por otro lado, en la "Francia libre" los ejemplares producidos se caracterizan por la fuerte presencia de Charles de Gaulle y de la cruz de Lorena, adoptada como símbolo del movimiento, así como por las continuas representaciones sobre la necesidad de expulsar lo antes posible al ocupante nazi del territorio nacional (véase F4).

Una vez finalizada la Segunda Guerra Mundial, asistimos al verdadero declive de este formato. La necesidad de comunicación una vez que concluyó la contienda se mantuvo unos años más hasta que los flujos demográficos se fueron reordenando en todo el continente. Sin embargo, pasada esa situación, como todo producto que se rinde al mercado, tuvo la obligación de irse adaptando a las nuevas realidades. Entre las principales causas que determinaron el detrimento tan acusado que experimentó en la segunda mitad del siglo XX jugaron un especial papel el clima de paz instalado en el continente desde el fin de la guerra y la utilización de otros medios de comunicación interpersonal más rápidos como el teléfono, extendido por esas fechas a todos los hogares, o la mensajería instantánea gracias a la llegada de Internet, que ha terminado por desterrar casi por completo la correspondencia escrita. Todo esto demuestra que la función para la que fueron planeadas ha sido plenamente usurpada por una infinidad de medios que han terminado por hacerse con la totalidad del sector de las comunicaciones. 


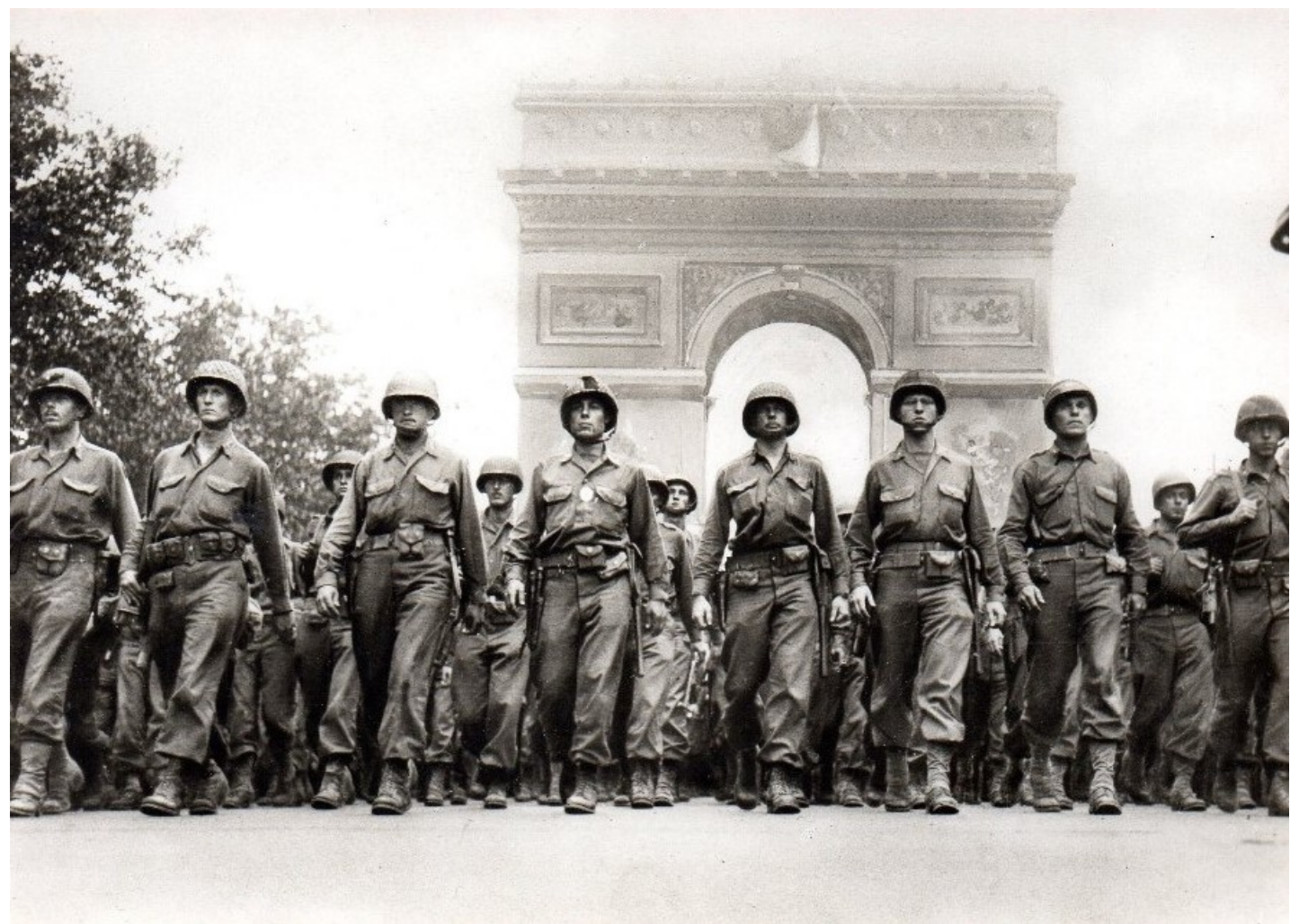

F4. L'Infanterie américaine à l’Etoile, 1944. Colección José Manuel López Torán.

\section{Conclusiones}

En los últimos años hemos asistido a una completa renovación en lo que respecta al acercamiento de los historiadores a las fuentes visuales. Si bien a la fotografía se le reconoció, hace ya tiempo, las múltiples posibilidades que ofrece para el conocimiento del pasado, otros soportes de características parecidas, como las postales, han tenido un recorrido más lento. Sin embargo, a la vista de los datos proporcionados, hemos podido comprobar las distintas ventajas que este formato presenta para el estudio de acontecimientos tan convulsos como son las guerras debido, en gran medida, a su fuerte presencia y a la intensidad de los flujos de circulación de ejemplares durante los periodos en los que se prolongaron las hostilidades.

En segundo lugar, con el estudio realizado se demuestra la estrecha relación que existe entre la tarjeta postal y el mundo de la guerra, gracias a las diferentes evidencias que se han recogido. Como se ha podido observar, la 
puesta en circulación del propio soporte estuvo intrínsecamente ligada al contexto derivado de la guerra franco-prusiana y sus años de mayor esplendor coincidieron con el desarrollo de la Primera Guerra Mundial. Junto a estos dos enfrentamientos armados, otros tantos aportaron novedades al citado soporte, como por ejemplo la Segunda Guerra Bóer y la guerra rusojaponesa al incorporar a las funcionalidades que ya tenía la postal su uso como vector de propaganda.

Por otra parte, a pesar de que tradicionalmente se ha situado en el final de la Gran Guerra el inicio del declive del formato, hemos podido comprobar cómo fueron nuevamente los distintos conflictos que se fueron sucediendo hasta el estallido de la Segunda Guerra Mundial los que elevaron las cifras de envíos de las tarjetas y los que le permitieron experimentar unos nuevos periodos de mayor protagonismo. De manera complementaria, ha sido posible detectar cómo los distintos cauces políticos que tomaron las naciones también tuvieron sus efectos en lo que respecta al volumen de producción, de manera que es posible determinar que, en el periodo de entreguerras en el siglo $\mathrm{XX}$, los niveles de producción y edición se mantuvieron superiores de edición en aquellos territorios cuyos regímenes desplegaron intensas campañas de propaganda.

Finalmente, gracias a la perspectiva comparada elegida para llevar a cabo la investigación se han podido determinar varios elementos de continuidad entre los distintos enfrentamientos analizados. Uno de los más evidentes es el aspecto temático, ya que ciertos motivos como las escenas de los campos de batalla, imágenes de tropas, representaciones o vistas de los daños ocasionados por la contienda han supuesto una constante a lo largo del tiempo. Estrechamente vinculada a esta cuestión encontramos la siguiente línea de continuidad detectada durante la investigación: la intensa utilización del soporte como medio de propaganda. Tal y como se ha podido apreciar, desde el momento en el que se descubrieron las numerosas ventajas que ofrecía el soporte, su explotación como vector de ideas se generalizó en los distintos enfrentamientos armados que se iban sucediendo. Por otro lado, un tercer elemento de permanencia que ha sido posible identificar es el interés 
por los dirigentes políticos y militares por facilitar al máximo la circulación de las postales. Tal y como se ha indicado, entre esas medidas se encuentran, por ejemplo, la gratuidad de los ejemplares para los soldados o el establecimiento de un servicio de correos eficaz que permitiera un intercambio fluido entre la retaguardia y los frentes.

En definitiva, hemos asistido al encuentro de dos caminos; la evolución de la tarjeta postal y el desarrollo de buena parte de las guerras contemporáneas. Dos caminos aparentemente distintos, pero que han demostrado confluir en un sendero común en el que ambos elementos se han aportado aspectos muy significativos el uno al otro.

\section{Referencias bibliográficas}

Almarcha, M. E., Fernández, Ó., Sánchez, I. \& Villena, R. (2007). Las tarjetas postales españolas entre repúblicas (1873-1939). En. R. Villena \& L. Crespo, Fotografía y patrimonio: II Encuentro en Castilla-La Mancha (pp. 22-45). Ciudad Real: Servicio de Publicaciones de la Universidad de Castilla-La Mancha.

Almarcha, M. E. \& Villena, R. (2019). Las tarjetas postales como registro de la memoria histórica. Revista La Tadeo De Arte, 5 (5), 178-203.

Bürgschwentner, J. (2013). War Relief, Patriotism and Art: The State-Run Production of Picture Postcards in Austria 1914-1918. Austrian Studies, 21, 99-120.

Carlson, J. (2009). Postcards and Propaganda: Cartographic Postcards as Soft News Images of the Russo-Japanese War. Political Communication, 26 (2), 212-237.

Cowlin, J. (2014). My propaganda \& satirical postcards of the Anglo-Boer War 1899-1902. Maldon: The Anglo-Boer War Philatelic Society.

Delhalle, S. (2011). L'image de la Belgique dans les cartes postales allemandes de la Première Guerre mondiale. Guerres Mondiales et Conflits Contemporains, 241, 51-62.

Guereña, J.-L. (2005). Imagen y memoria. La tarjeta postal a finales del siglo XIX y principios del siglo XX. Berceo, 149, 35-58.

Holt, T. \& Holt, V. (1987). I'll be seeing you: World War II through its picture postcards. Ashbourne: Moorland.

Lara, E. \& Martínez, M. J. (2009). El nacimiento de la tarjeta postal en Jaén (1902-1941): la construcción social de la imagen de una ciudad. 
Contraluz: Revista de la Asociación Cultural Arturo Cerdá y Rico, 6, 65-92.

López-Torán, J. M. (2017). La tarjeta postal como documento histórico: una aproximación visual a la Primera Guerra Mundial. Vínculos de Historia, 6, 286-306.

Martí, R. (2000). En campanya: les Targetes postals de la guerra civil, 19361939. Barcelona: Miquel A. Salvatella.

May, O. (2012). Zur Geschichte der Propaganda-Postkarte. Hildesheim: Franzbecker.

Moore, A. (2003). Postal propaganda of the Third Reich. Atglen: Schiffer Military History-Kew Gardens.

O'Connor P. \& Cohen, A. (2001). Thoughts on the precipice: Japanese postcards, c.1903-39. Japan Forum, 13 (1), 55-62.

Philippen, J. (1977). Histoire et charme de la carte postale illustrée. Paris: Relié.

Rapisarda, A. (1983). Il mondo in cartolina, 1898-1918. Milano: Rizzoli Editore.

Riego, B. (2011). Una revisión del valor cultural de la tarjeta postal ilustrada en el tiempo de las redes sociales. Fotocinema. Revista Científica de Cine y Fotografia, 2, 3-18.

Riego, B. (2019). Las imágenes como fenómeno cultural: una necesaria mirada en etapas para abordar los retos actuales. Historia y Memoria de la Educación, 10, 17-49.

Ripert, A. \& Frère, C. (2001). La carte postale: son histoire, sa fonction sociale. Paris: CNRS Éditions.

Sánchez, I. \& Villena, R. (2010). La tarjeta postal en la historia de España. En B. Riego, España en la tarjeta postal: Un siglo de imágenes (pp. 11-51). Madrid: Lunwerg.

Schulze, I. (2013). Los medios de comunicación en la Gran Guerra: Todo por la Patria. Historia y Comunicación Social, 18, 15-30.

Sturani, E. (2003). Le cartoline per il duce. Torino: Edizioni del capricorno.

Vries, G. de. (2016). The Great War through picture postcards. Barnsley: Pen $\&$ Sword Military. 